\title{
A STUDY ON THE DECORATIONS OF ILKHANI ERA: A CASE STUDY OF DOME OF SOLTANIYEH
}

\author{
Hooman Sobouti \\ Department of Architecture, Zanjan Branch, Islamic Azad University, Zanjan, Iran. \\ Young Researchers and Elites Club, Zanjan Branch, Islamic Azad University, Zanjan, Iran. \\ hoomansobouti@znu.ac.ir \\ Ali Ghasemi \\ Department of Architecture, Zanjan Branch, Islamic Azad University, Zanjan, Iran. \\ ali.qasemi1985@gmail.com \\ Hamed Ebadei \\ Department of Architecture, Zanjan Branch, Islamic Azad University, Zanjan, Iran. \\ Hamedebadi1988@gmail.com
}

\begin{abstract}
The Mongols, in the late sixth and early seventh century AH, invaded their surrounding territories and occupied large parts of the civilized world at that time, constituting the largest contiguous empire in human history in terms of land area. The Mongols' devastating attack on Iran took place in the early seventh century $\mathrm{AH}$ and resulted in the loss of many of our cultural heritage. Mongol rule and creation of Ilkhani family in Iran and Central Asia as well as the acceptance of Islam at the end of their rule and also the use of Iranian artists and arts would end in flourishing of architecture and its affiliates. Undoubtedly one of the most important surviving monuments of that period is the Dome of Soltaniyeh decorated by unmatched paintings on plaster, tiling, lattice brickwork, plaster and brick Mogharnas, plasters on fabric and inscriptions embellished with Quranic verses and traditional content. The current study which is a analytical/descriptive study, aimed at investigation of decorations of Ilkhaniera and its unmatched masterpiece of the Dome of Soltaniyieh.
\end{abstract}

Keywords: Ilkhani, decorations, Dome of Soltaniyeh

\section{INTRODUCTION}

In Ilkhaniera, the details of bricks' grouting, plasters and decorative tile work, continued with utmost accuracy in lines with advanced brickworks of prior period (Seljuks) and it was promoted. The highest flourishing of the tile art of that ear can be seen in Dome of Soltaniyeh. It can be said brickwork and decoration of buildings by carved bricks was common in Iran from the fifth century and it developed until the late sixth century (Weilber, 1967). In Ilkhaniera, brick arch cover ran into an extensive development of techniques and implementation and from this perspective, we can witness very eye-catching and well-formed domes like Dome of Soltaniyeh. The art of brickwork entered a very interesting phase of dome homes, in a particular mode, with the forms of falling and straight flower petals Potkaneh (two-layer domes) which can be seen in Varamin Mosque (Meshkati, 1970). Among the bricks used in the buildings of Ilkhaniera, the followings can be noted: ordinary brick, small brick, carved brick, and especial brick molds (Weilber, 1967). The Ilkhans after accessing the elements that created the Iranian monuments, were satisfied with their architectural style and their efforts were spent decorating buildings (Naeima, 1997). The Dome of Soltaniyeh was one of the buildings decorated in terms of tiling, painting on plaster, brickwork grid, plaster and brick Mogharnas, strips on the fabric, and inscriptions with Quranic and Hadith content, which is among the most important samples of the Ilkhaniera architecture significantly affecting the architectural monuments of the world, among which the Church of Santa Maria del Fiore in Florence can be noted (Kiani, 1995). According to a narration, it is said the Dome of Soltaniyeh is designed based on the 
design of the tomb of Ghazan Khan, which is itself inspired by the tomb of Sultan Sanjar, however its plan is square, while the dome of Soltaniyeh is octagonal. On the other hand, the innovative aspects of this building have turned it into one of the most significant Islamic monuments in the world (weilber, 1986) (figure 1).

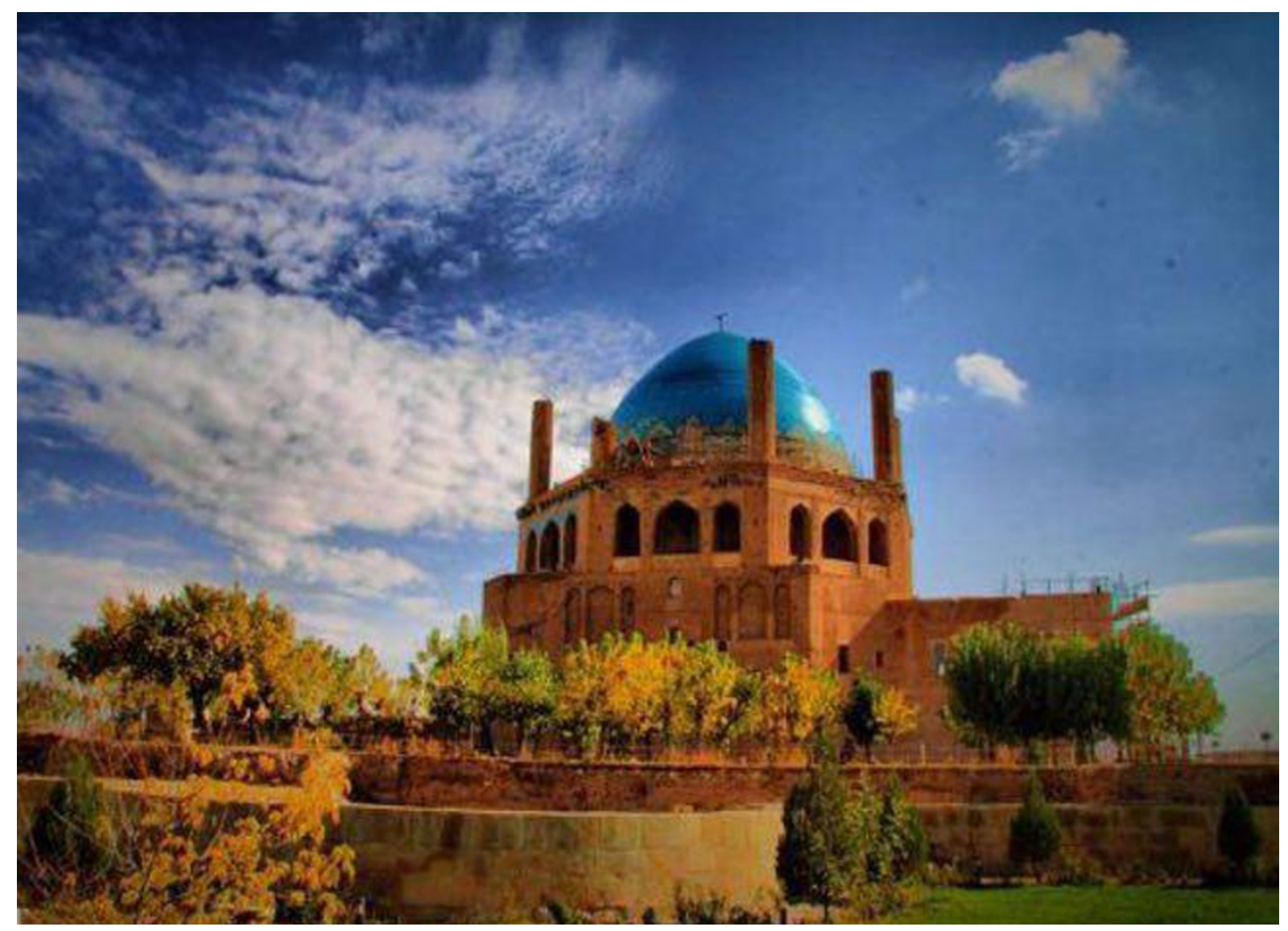

Figure 1: a view of the dome of Soltaniyeh

\section{THE ARCHITECTURE OF THE ILKHANI}

The construction works style of the Ilkhanihas been directly adapted from the Seljuk period architecture style. Seljuk and the Ilkhaniarchitecture are similar to each other in terms of indication and manifestation. In the Seljuk period as well as the Ilkhaniera, religious buildings such as mosques and religious shrines and tombs were preferred over the non-religious buildings. This is a sign of the economic prosperity of the era. In Seljuk era, the architecture and design werein the testing phase, while during Ilkhani era, the major issue has been incorporation of decorative and Construction shapes. The architects of the ilkhani era, all adopted the shapes, materials, and construction methods of Seljuk era. The tomb was important in the Seljuk period and during the Ilkhani era, it was used as a template. With the assumption that the Seljuk era corresponds with the romantic style in terms of time and number of years of romantic style, and the Ilkhani era corresponds with the Gothic style, there was no such a revolution in thinking and shape (form) that lead the romantic style to the Gothic style, in Iranian architecture. This continuity of style is in a way that it can be said the Seljuk architecture is a primitive form of the Ilkhani architecture and during a 300-year period, Iranian architecture has passed the regular course of evolution (Weilber, 1967). Ilkhans, until the end of their, didn't show due respect to the architecture. In other words, their action was limited to the judgments and orders prepared by their ministers. These rulers until the late Ilkhani era, only spent a limited time in their urban palaces and instead they set up their court to the demand of season in the tropical plains and cold slopes of mountain-foots. Anyways, the last rulers of the dynasty expressed a very high personal desire to plans and creation of a lot of important historic buildings and it led to the creation of an overall unity in the general style of Iranian architecture. Constructing these massive structures, the 
construction plans of that time were used, however in a scale which was larger than all the efforts of former eras. The grandeur of the monuments created in Tabriz and Soltaniyeh arose the need to invite the artists and builders from across the country. Thus, all architects and interns and master craftsmen were aware of the techniques and secrets of their colleagues and when the building was completed and they returned to their own country, they used the advanced skills of their time in the construction of other buildings. Thus, even after the fall of the Ilkhans, the great architectural styles of this era did not vanish, yet it continued and spread around the country, setting the stage for massive construction activity Timurid period.

\section{GEOGRAPHY AND FEATURES OF THE DOME OF SOLTANIYEH}

Soltanieh Dome is three hundred kilometers from Tehran and is located in the city of Soltaniyeh, near Zanjan and shines like a dice in the remote desert. The tomb of Soltaniyeh as one of the monuments was constructed on the orders of Sultan Muhammad Khodabande (Aljaito) the Mongol ruler, from $703 \mathrm{AH}$ to $713 \mathrm{AH}$ and Khaje Rashideddin Fazlollah Hamedani supervised its construction. The octagonal building height is 48.5 meters and its internal opening diameter is $25.5 \mathrm{~m}$.After the Church of Santa Maria Delfiore $(86 \mathrm{~m})$ and the Sophia Mosque in Istanbul (56 meters) it is the third highest dome is the world (Sobuti, 1996). The dome's infrastructure is known as "Yazdi Bandi". "Shekanj" that changes the square under the dome into a circle, or the type of the dome above Soltaniyeh (Chileh) are among the features of Yazd City. "Chileh" is the same as the silo (The jug-shaped domes can be built, highly resistant and can stand on their own like an upside-down bowl). It is because of the form of the dome that it stands firm (Mostofi, 1985). The dome of Soltaniyeh decorations are of two types: One of them is the principles that are formed from pottery pieces and small pieces of brick which is called knotting. Another type is a combination of tile and brick knotting which is called "Maaqali". Decoration of the triangles with mosaic tiles is very delicate. The triangles are set by highly detailed and beautiful mosaic (the mosaic tile is a tile whose pieces are cut in non-geometric form and put together). A simple mosaic work that has a long history in Iran, was used for the first time in Azeri style of dome of Soltaniyeh (Sobuti, 1985).

\section{THE BRICK DECORATIONS OF SOLTANIYEH DOME DECORATIVE BRICK MOLDING}

This type of bricks has been used in four southern, eastern, northeastern, northwestern porches in harsh knots and their ornamental elements of these knots are very diverse and complex. The bricks have been used in the form of six and five, or six strap-piece, slim legs, Sally, and Iranian star. Their internal designs are constituted of arabesques, flowers, and plants with diverse combination. This type of decoration is a combination of six and five knots.

\section{CARVED BRICKS DECORATIONS}

The carved decorative bricks can only be seen on the eastern and southern porches on the two fronts. Here, the decorating technique is the instrument and word style. The instrument for these decorations is the carved brick. The line between the bricks is cut evenly and equally, in a parallel manner and with this implementation, the designs' aspects have emerged with the highest precision. The overall composition of a star-filled ornament has been branched from a 10-section star. The star surface is filled with brick mold arabesque. The turquoise tiles are used in this style for word decorations. The total mentioned decorations on this porch are surrounded by a margin of mosaic tiling with the arabesque designs and this combination has given this porch a certain charm (Fazlollahi \& Kolaei, 2014).

\section{PRE-CUT BRICK DECORATIONS}

Another part of brick decorations are the words and brick inscriptions and the type of these words which are known as "Jali" has manifested the Quranic verses with this script and style. The writing style of these scripts is in a way that after the preparation of mud bricks they are laid out on a plain surface and then the words are separated by sharp tools and after being cooked, the words and letters are put and installed wherever needed. Today also, exactly the same technique is used for reconstruction of Soltaniyeh decorations (figure 2). 


\section{DECORATIVE BRICKWORK}

The components and the parts of the dome of Soltaniyeh is as if it is the hotbed and a manifestation of the artistic genius of its masons and craftsmen and through this, they have showed off their art whenever they had the chance. In this regard, the application of decorative brick is significant. The brick mogharnas-work by beige and red bricks and combination of the two colors on the two porches of first floor on the east and west sides have created unique designs. This technique of decorating has been used on the first floor of the Northwest porch on a flat surface. Another Brick decorating style of the building is known as the Dormant and the combination of the beige and a red color brick by the craftsmen has given it a special and unique manifestation.

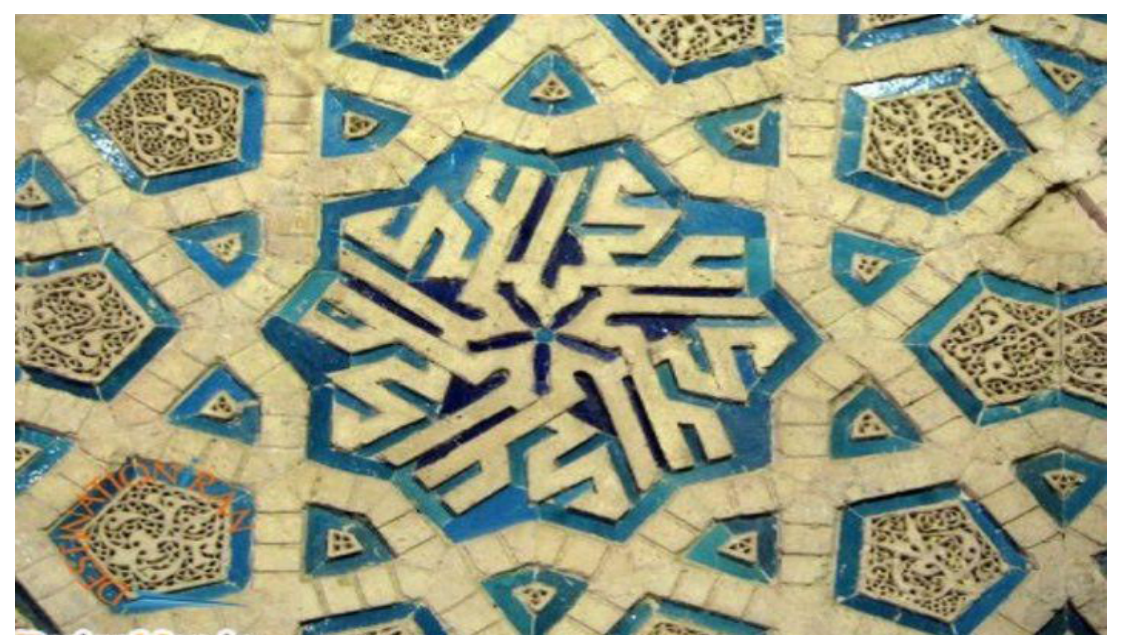

Figure 2: the precut brick decorations

\section{THE BRICK DECORATIONS BY COMBINATION OF TILING}

The invention and creation of "Maaqal" lines and patterns is one of the artistic phenomena in the Islamic era architecture. In the dome of soltaniyeh, this technique of decorating can be seen to the extent of flourishing. The combination of brick and tile decoration generally belongs to the first layer decorations which have been implemented craftily simultaneous with the physical progress of the building. This style has been used on the all 8 porches of the first floor and as a second layer, the mentioned decorations have been covered by hexagonal tiles on the Southwest, West, and Northwest porches. The southeast porch is covered by gypsum plaster. For the South, Southwest, West, Northeast porches, the decoration method is decorative patterns and it is the scripts and texts for the Southeast and Northwest porches. This type of decoration has been also used on the dome's stem and Allah's names and the related words have emerged (figure 3 ). 


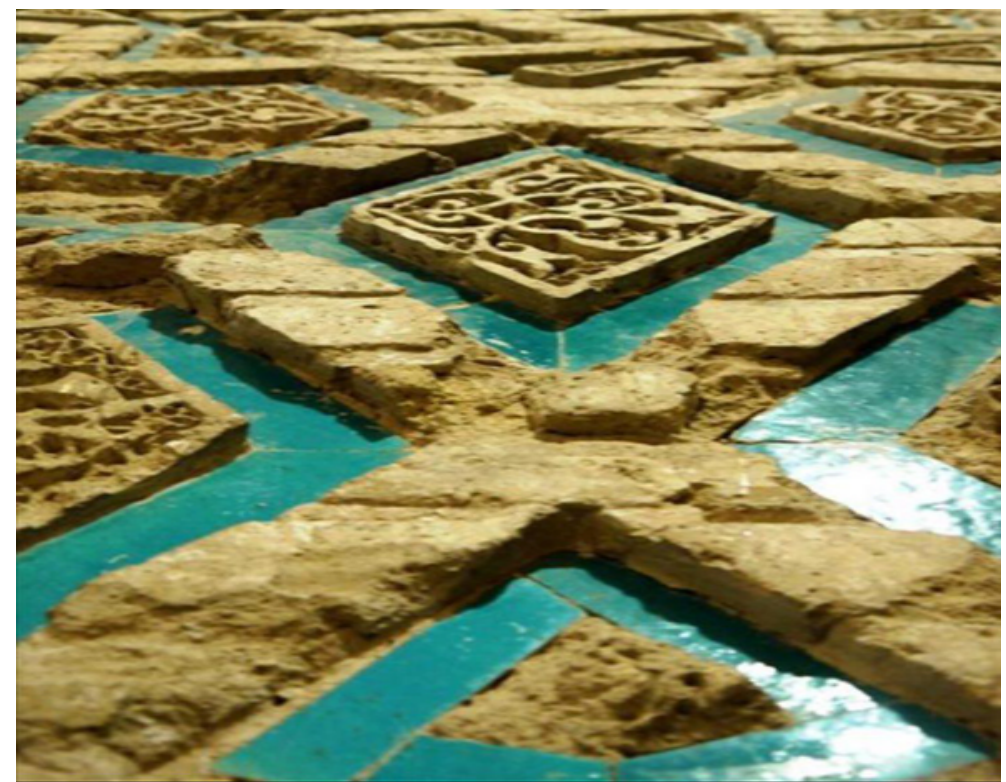

Figure 3: the decoration from combination of brick and tile

\section{GYPSUM PLASTER DECORATIONS \\ ENGRAVED PLASTER DECORATIONS}

The carved plaster decorations can be seen on the ceiling of all the 24 porches on the second floor. This type of decoration is completely different from the method known as "stamping" and requires a special precision and skill during the implementation. In addition to complying care about designs, precisely control ling the depth and created surface of the underside is mandatory. This type of decoration is more successful than that of used in mosques Ashtarjan and Faryumad and the tomb of Sheikh Jaam. Each of the porchs' ceilings, with maintaining the general method of work in terms of the patterns, has its own specific design. Generally, the ceiling design is inscribed in beautiful boxes whose designs have been created by the method of engraving. Their patterns have been also created by arabesques, plant flowers, inscriptions, and the Quranic verses and have several designs. The width of these decorative borders can vary from ten to twenty centimeters. The Western and Northwest porchs ceiling have been decorated with geometric patterns and carved plant flowers besides the names of Allah. These designs are generally branched from a motif called "Shamseh" which is located at the middle. On the western side, instead of the names of Allah, the geometric and plant designs have been used with the different that here the area is rough and placed in six-pointed star-shaped designs inside the hexagonal boxes in a way the mentioned motifs are being separated by decorative strips. At the back of the central arches, innovative motifs and imagery have been created by combining white and ocher colors which have doubled its charm. On the north side porch ceiling, on the central part, are inscribed the word of Allah with the beautiful script "Sols" and the word Muhammad is in Kufic script which is repeated six times. The surface of the back of arches is presented as an artistic masterpiece on this porch using the beige and ocher and the colorful designs and motifs with the combination of gypsum plaster, brick, and color. Northeast porch decoration in the middle of the arc is a verse from the Qur'an in Kufic script which is repeated 16 times with a cross-like shape in the middle of each motif. In the middle of this decorative margin, there is a circle in the middle of which the great word of Allah is written with the word Mohammad repeated 8 times around it, in Kufic script (Zaki, 1998). The southeast and east porches ceilings is comparable to that of northeast with the different that in the middle of the design, the word Mohammad is written in "Sols" script and the dark green color is used for the internal motifs of the design. The back side of these plastered arches is embellished by geometric designs in the middle of which are located sixornate flowers (Fazlollahi \& Kolaei, 2014)(figure 4) 


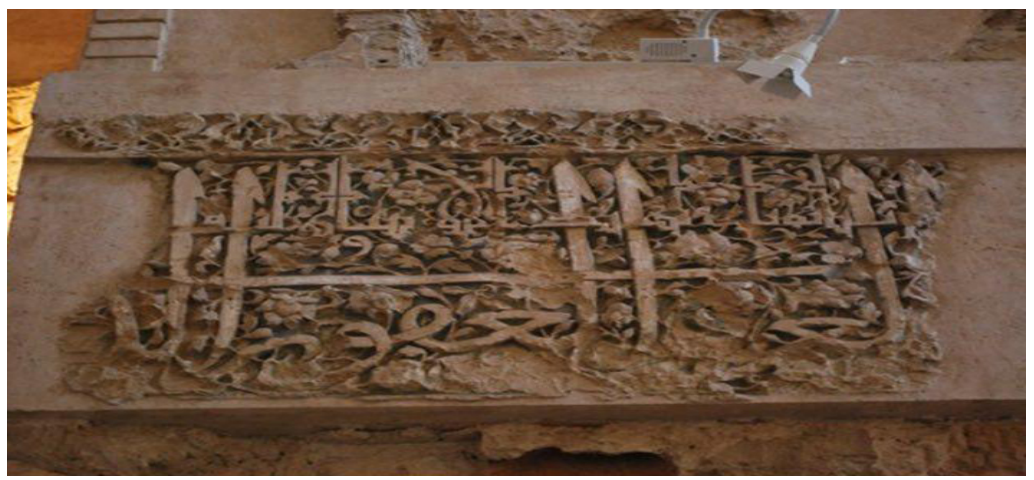

Figure 4: the carved plaster decorations

\section{NAQARI PLASTERED DECORATIONS}

The plastered decorations in Naqari style are very rare in Soltaniyeh building except for the decorative margin of the ceilings on the 8 porches. Only in one case, at the top of the floor porch, it can be seen on the northwest side with the simple arabesque design. Decorative margins on the porches of the second floor contain arabesque motifs and a design known as "Miandar" which is an artistic phenomenon of Greece. These designs have been implemented as one-line and two-line.

\section{ADJUNCT PLASTER DECORATIONS}

The adjunct decorations are another kind of decorative styles in this historical building. The process is like that on the desired surfaces after framing, the motifs and words are written on their place using gypsum. The thickness of the decorations is very low in this style and does not exceed millimeter. Normally, using the color for the field of the molding, besides making it more attractive, greatly helps with highlighting the designs. The middle inscription inside the dome is among the decorations of this type (Zargham, 1992). The "Fath" Surah is written in Jali script on this script around the sides of these porchs. On top of this inscription, there is an inscription in which the famous design Rooz (lotus) have been repeated and extended along the inscription. These motifs with maintaining the style of decorations, have been painted in ocher color with the margins of the motifs painted as black.

\section{PATCH PLASTER DECORATIONS}

This type of decoration is different from the adjunct plaster in terms of technique. The working method is in a way that the needed surface is reflected and then the plasterer lays the gypsum on the motifs. Where the images and words fall, the preliminary plan has emerged. The thickness of the motifs is higher in this style compared to the adjunct type ad in order to prevent falling of the motifs, the general design is strengthened after implementation by the use of elements like iron nails to add to the adhesiveness to the place. Among the decorative elements in this style are very large bergamonts in forty-meter measurement placed in the middle of the dome. The design of these decorations which are 15 is of arabesque type and all the surfaces of this design, in spite of the high number of bumps, are painted in dark ocher color (zargham, 1992). Plaster-work in patch style suing different colors, is among the most charming decorative designs of Ilkhani era and the used colors are as follows: Light blue, green, gold, red, ocher and brown.

\section{STAMP PLASTER DECORATIONS}

The main decoration of this method is visible on the distance between the bricks. The style is like that with leaving a blank row between the bricks in vertical and horizontal rows which is uniform and in the same regiment, simultaneous with the decorations, this blank space is filled by plaster and the desired motif which has been carved previously, is installed on the given place. These motifs are common in the dome of Soltaniyeh and these motifs are of arabesque and geometric type embellished with the names of "Ali" and "Mohammad" in Maaqal script. This type of decorations can be seen on the pillars of the 24 porches on the second floor and the body of the communication corridors in the first floor (Fazlollahi \& Kolaei, 2014)(figure 5). 


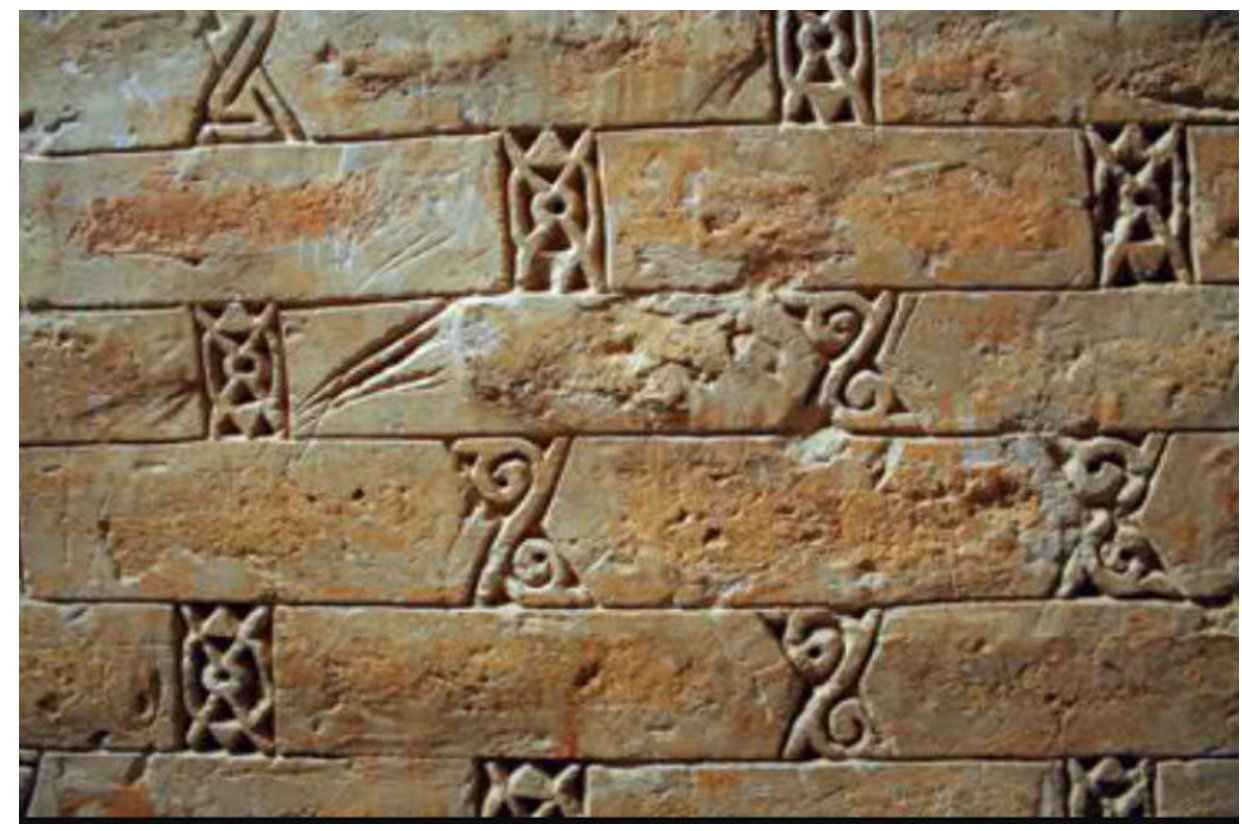

Figure 5: stamp plaster decorations

\section{THE CHARACTERISTICS OF TILE DECORATIONS IN DOME OF SOLTANIYEH}

In the main view of the dome and in the middle of the stem, two meters above the floor, the strengthening decorative elements from the combination of tile and brick have emerged, with the names of "Ali" and "Mohammad", and the great word of "Allah" extended around the dome. All these decorations have been surrounded by two rows of black tiles on the top and bottom sides and the distance between these lines, the tiles have been used in the straight style and the bricks in falling style. The words have been made by combination of them. The distance between the tiles and bricks are minimized so that grouting is generally not possible. On the Western and northwest Fronts, in the same way, five and a half decorative bergamots have been implemented and the words margins have been surrounded by two rows of tiles one of which is green and light and the other is dark blue. In the middle of these half-bergamot, the words Mohammad and Ali are so charming to the eyes. The words tiles colors are blue and green and the dome's color is turquoise. The dimensions of the tiles are measured from five to twenty centimeters. The 8 minarets of on the third floor have been decorated by tiles. None of the minarets exist in a complete structure today, however the evidence indicate they were decorated by tiles. Investigating the four remaining minarets on which there are some tiles remainig, it can be inferred that the method and decoration style have been the same for all the tiles and the tiling was done in dormant style and among them, the dark blue tiles have been used for creating the Maaqal lines. The size and color of the eight minarets are comparable to the dome itself. The neck above the 8 porches on the second floor, backside of the mentioned 24 arches and their decorative margins have created the most attractive tiling work in the dome of Soltaniyeh (Zaki, 1998). The necks in the building are composed of harmonious Mogharnas and by creation of the open and close angles, has created interesting penumbra. The congruence and dimensions of the Mogharnas' elements to the perspective and height of the work indicates the knowledge and approach of the designers and builders on the "science of mirrors". The result is that the mentioned parts using mosaic tiling and by application of the light blue, dark green and black and by creation of geometric patterns, have one of the most beautiful architectural elements. This type of decoration has been badly damaged on the the East, Southeast and Southwest fronts and only in the north and northwest fronts, it has remained relatively right. The neck of the 8 minarets is among the fallen tiling. Thearchaeological evidence indicate that before fall of the finial, there were necks in Mogharnas style on the end of the minarets which are comparable to the dome's neck (Zaki, 1998). The use of tile on the exterior body of the Aljayto octagonal tomb is just in the eastern and western sides. The East side is dominant to a wide floor whose the southern part has constituted a part of "Abvab Al-Berr" elements. All the surface of this side, on the floor, have been covered by stone plinth, knot work full of decorative tiles, and a 
kind of decorative strapping. The extension of these tile strappings in harmonious and lofty arcades and combining them with the eastern windows has brought indescribable beauty. On the west side behind the windows arch appears a brief tiling. On the inside, the tile work can be studied in two distinct layers. In general, the first decorative tiling can be seen in mosaic style in the colors dark blue, light green and black, white and yellow with designs generally as the complex geometry similar to angled arabesque and combinations of star-like motifs. On the ground floor on either side of each 8 pillars, there have been installed sixteen facades. These facades have been decorated with mosaic tiling techniques with chain design and in dark blue, light green and white colors. The ground floor porch margins belong to the first period-style that is mosaic tiling and these ornaments have been plastered in the second period. On the surface of the arc on the second floor, for the north-eastern, eastern, northern and southwestern porches mosaic tiling have been beautifully implemented using tiles in blue, white, green and yellow. The motifs of northeast porch have been surrounded in triangle white and blue mosaic boxes and the motif of five and a half octagonal star is extended and repeated on the surface of the arc. The southwest porch motifs are made by repetition of large and small stars and work style and color of the tiles is the same of the arc. The eastern porch motifs include 12-point stars and Iranian 5-point stars by combination of which, innovative motifs have been created. On the south porch, complex decorations using the tool and word style have been created with the tile as the tool and brick as the word. Most of the second layer decorations include designs on the plaster and decorative inscriptions all of which implemented on straight surfaces and they can be seen on the eight porches on the ground floor (figure 6).

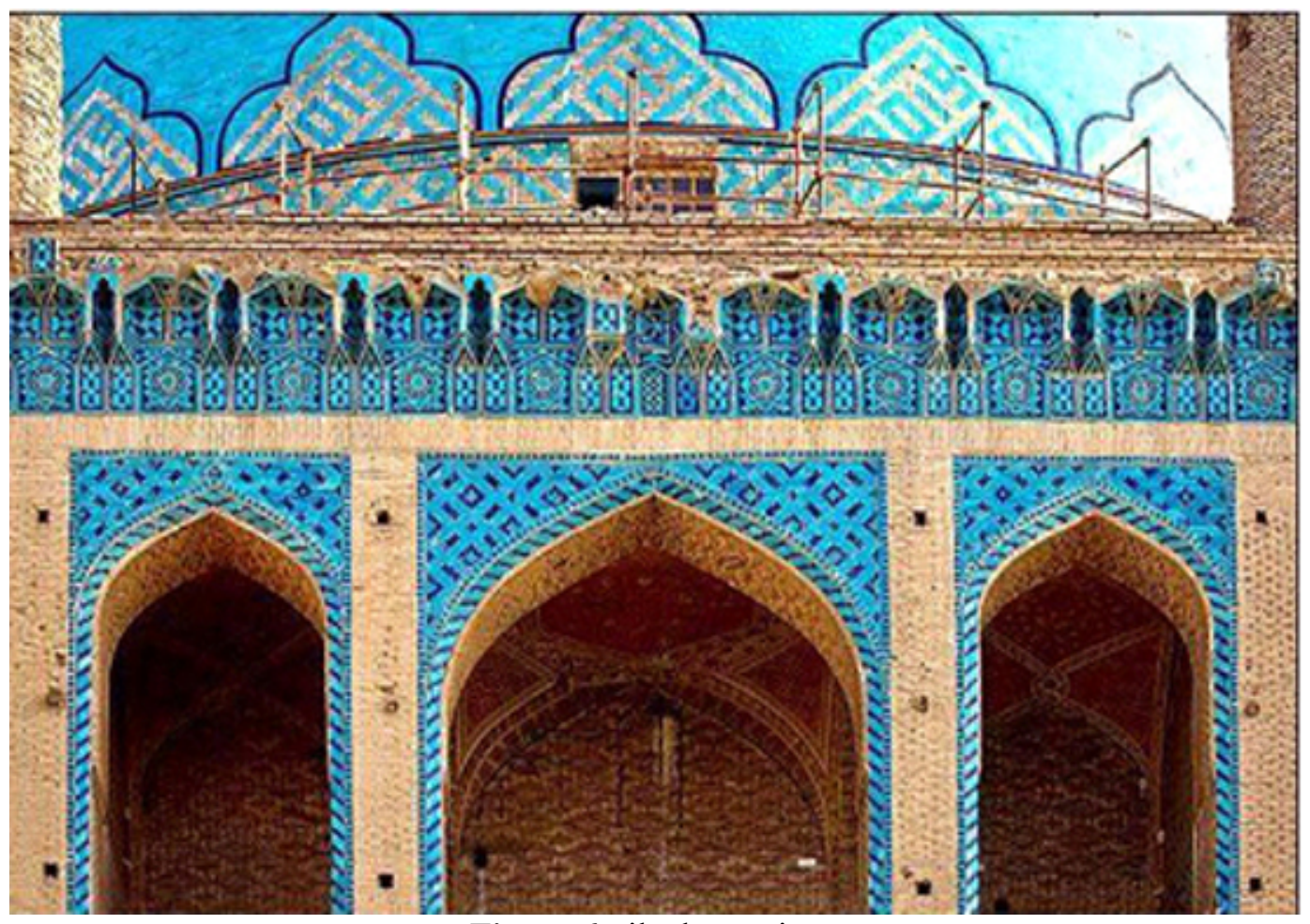

Figure 6: tile decorations

\section{COLOR DECORATIONS AND PAINTING OF SOLTANIYEH}

This element has gone through its first experiences in Iranian architecture in this building and has been very successful. The south porch margin decoration dominant to the "Torbat Khane" is arabesque motif which is painted in blue, golden, and brown and has been repeated. All the inscriptions of the inside of the dome on the sides of Southwest, West, Northwest, East, and Ground Floor porches, the bergamots and Shamseh, the vertical inscriptions of the porches, and the inscriptions on the floor inside the internal front which all belong to the second layer decorations, have been painted white with light blue background. The decorative bergamots of the middle part of 
the dome and the plaster work of the first floor booths are painted ochre. Generally, ground and first floors of the second period inscriptions are written using paint (Fazlollahi \& Kolaei, 2014).

\section{STONE DECORATIONS}

In the Aljaito Tomb building, except the green stone plinth that mostly play static role, there are no decorations. Only in one case, which is a functional element and that is second floor bump, which is exposed to atmospheric agent. These bumps has changed to wooden bumps on the first floor booths and still three "Maajar"(a type of Islamic scripts) remain on North, East and South-West booths and they have been decorated by 8 - and 12-knot decorations.

\section{EVALUATION OF THE DOME OF SOLTANIYEH'S INSCRIPTIONS}

Soltanieh dome inscription is one of the reliable sources and elements that are important in defining this monument. Especially, the decorative element "script" has been raised as an artistic phenomenon in religious buildings and it is factor for pushing people into the kingdom of heaven and thinking about the philosophy of the vast universe and the basis of life. Therefore, artists have proposed its function as a dynamic factor of art (Eghbal Ashtiani, 1986). The inscriptions on the west, northwest, north, southeast and southwest porches are among the most beautiful scripts of this monument which are significantly important in terms of creating space and greatness in the building due to verticality on the words. Historically, it is one of the reliable sources for datelining the ornaments on the second layer. With writing the name "Khaje Tajeddin Alishah" on the end of the inscription, the theory that the decorations may not belong to the Ilkhani would be ruled out. The mentioned inscription is in the beautiful script "Sols Jali" in white, on a light blue background starting from six meters above the porch's floor and after an arc-like move in the level and symmetrical measures, has ended at its starting point (Kasaei, 1975). The longest inscription in this monument is the one $360 \mathrm{~cm}$ from the floor with $75 \mathrm{~cm}$ width, extended around the building and continued following the porches and stems. The color of this inscription is ocher with cream color background and the words' margins have been somewhat bumped and painted in dark blue. On the second floor of the east porch and on the surface of the arc, there is an inscriptions made by the precut bricks on the mosaic tiling background painted in green and blue. The inscription's width is the same as arc's surface on the end. This surface is initially divided into two parts and the ends of the words meet each other in the middle of the inscription creating a beautiful star-like motif. On this inscription can be seen the verse 25 of the "Baqareh" Surah (first Surah) in simple Kufic script (Kasaei, 1975). On the southeast and north porches, there have been written a Hadith from Holy Prophet. On the surface of the pillars of the southeast and southwest porches, decorative designs in the shape of bergamot in blue have been designed. The overall lines of these patterns is arabesque among which several "Ali" names in "Sols" script can be seen, with the words "Bubakar", Omar", "Osman", "Ali", "Hasan", and "Hosein" repeated around them. The existence of the names of the Rashedin Khalifs rules out the inscriptions attachment to the Safavid Era (Kasaei, 1975). On the second floor of the east porch, there is a beautiful inscription in Kufic script made of precut bricks, on a mosaic tiling background designed with Checkerboard pattern. The sentence "Al-Soltan Mohammad Aljaito" have been repeated 7 times on the plaster in blue color, on the northwest porch of first floor. Among the most beautiful inscriptions of the first layer is the sentence "Sobhan Allah" in Maaqal kufic script. This inscription has been created from the combination of brick and tile in level, on the internal surfaces the east porch. The words are made of brick and repeated 5 times. On the surface of the northwest porch, the word "Ali" has been repeated in diamonds and on the other hand, the word "Mohammad" has been repeated 4 times in Maaqal Kufic script, extended on the pillar's surface till the end of the porch at the top of the second floor. On the exterior view of the east porch, some lines in the style of designing calligraphy can be seen. Two plaster inscriptions in small and large fonts can be seen in "Torbat Khaneh"., The inscriptions of this section, as well as its other decorations, are completely gone. The small font inscriptions are in Kufic script and sue to the severity of the damage, cannot be read, however in the large font, the "Jomaah" Surah can be seen in "Sols" script. The inscription is mostly damaged and gone, however by reconstruction of the remaining sentences and signs, the exact location od the words can be identified. The inscription's starting point is left side of the "Tortbat Khaneh" sanctuary and the words "Al-Qoddus" and "Al-aziz" have remained on the first niche on the left side of the sanctuary. The words "Yahmel Asfara" can be seen on the top of "Torbat Khaneh" 
entrance. Anyways, another part of the Aljaito's tomb inscriptions are still illegible. Reading these inscriptions can greatly help exploring the truth and identifying this great monument and it has a great importance, requiring reconstruction and repair (Maleki, 2011).

\section{CONCLUSION}

The monuments left by Ilkhani stage now belong to the history of Iranian architecture. A stage although coincided with Mongol invasion on our country and demolishing the buildings from the past, undeniable in terms of several great monuments for the future, by establishment of Ilkhani and adaptation from Seljuk era. The results of the studies indicate that undoubtedly, the dome of Soltaniyeh, with its decorative masterpiece, has provided the highest decorations for the future Islamic Iranian eras. The role of Ilkhani and their support from the architects and artists of that era for using and flourishing the scripts and the use of inscription as an important element in moldings, especially for the sanctuaries, the high embellishment of the patterns, the knotted Kufucs, and the use of triangle arcades in plaster sanctuaries and mogharnas besides the illuminated motifs manuscripts in decorations, cannot be denied.

\section{REFERENCES}

Eghabal Ashtiani, A., (1986), "the history of Mongols", the Translation and Publication Publishers, $6^{\text {th }}$ Ed., Tehran.

Fazlollahi, M. \& Kolaei, A., (2013), "studying the decorative visual features of dome of Soltaniyeh", the national Conference of Architecture, Shahid Mofatteh University.

Kasaei, R., (1975), "the repeated decorative layers in dome of Soltaniyeh", Iranian Journal of Culture and Literature, No. 16.

Kiani, M.Y., (1995), "Iranian architecture during the Islamic era", SAMT publications, Tehran.

Meshkati, N.A., (1970), "the list of ancient and historical places of Iran", the National Organization of Ancient Buildings Maintenance, Iran.

Naeima, Gh., (1997), "Dezful, the city of bricks", $1^{\text {st }}$ ed., the National Works Institute, Tehran.

Maleki, M., (2011), "Soltaniyeh through the history", Danesh Publishers, $1^{\text {st }}$ Ed., Zanjan.

Mostofi, H., (1985), "the select history", Amir kabir Publishers, $3^{\text {rd }}$ Ed.

Sobuti, H., (1996), "the history of Zanjan City", Tavana Publishers, $5^{\text {th }}$ Ed., Zanjan.

Welber, D., (1986), "the Islamic architecture of Iran in Ilkhani era", translated by Faryar, A., Elmi Publishers, Tehran.

Weilber, D., (1967), "the Islamic architecture of Iran in Ilkani era", translated by Faryar, A., $1^{\text {st }}$ Ed., The Institution for Translation and Publication of the Books, Tehran.

Zaki, M.H., (1998), "the Iranian art during Islamic era", translated by Aghlidi, M.H., Nedaye Moaser Publishers, Tehran.

Zargham, SH., (1992), "the façade of dome of Soltaniyeh", a thesis for master degree, Faculty of Literature and Humanities, Tehran. 